\title{
Characterization of the Disruptions of Prepulse Inhibition and Habituation of Startle Induced by $\alpha$-Ethyltryptamine
}

Diana L. Martinez, M.S. and Mark A. Geyer, Ph.D.

\begin{abstract}
Alpha-ethyltryptamine (AET), a monoamine oxidase inhibitor and potent monoamine releasing agent, has been sold illicitly as a substitute for the entactogen

3,4-methylenedioxy-N-methylamphetamine (MDMA), and is the first example of an indolealkylamine analog demonstrated to substitute in MDMA-trained animals. Previous studies have demonstrated that MDMA and AET have similar effects on unconditioned motor behavior in rats. Furthermore, the locomotor-activating effects of both MDMA and AET are blocked by pretreatment with fluoxetine, a selective serotonin (5-HT) uptake inhibitor, suggesting that the two compounds may share a presynaptic mechanism of action. This study examined the effects of AET using measures of startle plasticity,

specifically prepulse inhibition (PPI), and habituation. PPI, a measure of sensorimotor gating, is reduced in rats treated with hallucinogens, 5-HT releasers, and dopamine agonists.
\end{abstract}

KEY WORDS: Startle; Prepulse inhibition (PPI); Habituation; Serotonin (5-HT); Fluoxetine; $\alpha$-Ethyltryptamine (AET); Obsessive compulsive disorder $(O C D)$;

3,4-methylenedioxy-N-methylamphetamine (MDMA)

Previous studies in rats have shown that the substituted amphetamine derivative, 3,4-methylenedioxy-N-methylamphetamine (MDMA) and the tryptamine derivative, $\alpha$-ethyltryptamine (AET) have some similar behavioral

From the Departments of Neuroscience and Psychiatry, University of California, San Diego, La Jolla, CA.

Address correspondence to: Mark A. Geyer, Ph.D., Department of Psychiatry, 0804, University of California, San Diego, 9500 Gilman Drive, La Jolla, CA 92093-0804.

Received May 10, 1996; revised August 23, 1996; accepted September 4, 1996.
In contrast, startle habituation is reduced in rats treated with hallucinogens and 5-HT releasers. AET $(1.25,2.5,5$, and $10 \mathrm{mg} / \mathrm{kg}$ ) decreased PPI of acoustic startle and reduced the habituation of tactile startle. To determine whether AET produces these effects via pre- or postsynaptic actions, fluoxetine $(10 \mathrm{mg} / \mathrm{kg})$ was used as a pretreatment. By itself, fluoxetine did not disrupt PPI, but did reduce startle habituation. Fluoxetine pretreatment prevented the $A E T$-induced disruption of PPI and reduced the AETinduced disruption of startle habituation. Combined with previous findings, these results confirm that $A E T$ produces behavioral effects that mimic those of other indirect 5-HT agonists and that the effects of AET on startle plasticity are due to the release of presynaptic 5-HT. (C) 1997 American College of Neuropsychopharmocology

[Neuropsychopharmacology 16:246-255, 1997]

effects (Krebs and Geyer 1993) despite being derived from different chemical families (Figure 1). For example, AET is the first example of an indolealkylamine analog demonstrated to substitute for MDMA in rats trained to discriminate the effects of MDMA (Glennon 1993). Similarly, AET has been reported to produce MDMA-like effects in human subjects and has sometimes been sold as a substitute for MDMA on the street (Federal Register 1993). AET is both a monoamine oxidase inhibitor and a potent monoamine releasing agent (Baker et al. 1980). In studies of exploratory and locomotor behaviors, AET produces a behavioral profile that is similar to the effects of serotonin (5-HT) releasers such as MDMA and dissimilar from the effects of dopamine releasers such as amphetamine (Krebs and Geyer 1993; Geyer 1995). 
Furthermore, the similar locomotor-activating effects of MDMA and AET are blocked by pretreatment with fluoxetine (Callaway et al. 1990; Krebs and Geyer 1993), suggesting that the two compounds may share a common mechanism of central 5-HT action. In addition to changes in locomotor and investigatory behaviors, MDMA-like compounds also produce specific effects in startle reflex paradigms (Geyer and Callaway 1994). As will be detailed, previous studies have found that MDMA produces dose-related increases in acoustic and tactile startle habituation (Kehne et al. 1992) and decreases in prepulse inhibition (Mansbach et al. 1989; Padich 1993).

The present study was undertaken to examine further the serotonergic influencing aspects of AET using the startle response paradigm (see Geyer et al. 1990 for review). The startle response is a reflexive response to strong exteroceptive stimuli (e.g., auditory or tactile) and demonstrates plasticity in the forms of prepulse inhibition (PPI) and habituation, both of which are readily observable in humans and animals. PPI is the normal suppression of the startle reflex when the startling stimulus is preceded by a weaker prestimulus (Hoffman and Searle 1968; Graham 1975). Habituation refers to the decrement in responding when the same stimulus is presented repeatedly in the absence of any contingencies and has been deemed the simplest form of learning. Studies of PPI and habituation of startle have proven to be useful methods for assessing the behavioral influences of various psychoactive substances, environmental or experiential manipulations, or psychiatric conditions on reactivity, habituation, or sensorimotor gating. An advantage of using such models is that they have been studied in depth and thus their modulation via pharmacologic manipulations, especially monoaminergic systems, is well documented. In particular, PPI and startle habituation have been used as operational measures of sensorimotor gating and habituation functions, respectively, in both human and animal explorations of attentional deficits characteristic of schizophrenic patients (Braff et al. 1978, 1992; Braff and Geyer 1990). In addition, the pathophysiologies of obsessive compulsive disorder (OCD) and Huntington's disease include abnormalities in neuroanatomical regions that modulate PPI in rats. Accordingly, deficits in PPI have been observed in patients with both these disorders (Swerdlow et al. 1993, 1995), as well as in patients with schizophrenia (Braff et al. 1992).

Previous studies have found that 5-HT modulates startle reflexes in a modality-specific fashion (Geyer et al. 1978; Davis 1980, 1986) via multiple 5-HT pathways and 5-HT receptor subtypes (Davis et al. 1986; Sipes and Geyer 1994). Consequently, the behaviors elicited by the administration of a 5-HT-releasing drug could be the result of the different combinations of pathways and receptors influenced. It has been demonstrated that normal rats become deficient in PPI if 5-HT function is aug- mented. Notably, selective $5-\mathrm{HT}_{1 \mathrm{~A}}$ agonists including 8-hydroxy-2-(di-n-propylamino)tetralin (8-OH-DPAT), buspirone, or ipsapirone have been shown to disrupt PPI potently while having no effect on startle reflex magnitude (Rigdon and Weatherspoon 1992; Sipes and Geyer 1994, 1995a). Agonists at 5- $\mathrm{HT}_{2}$ receptors also disrupt PPI. For example, the 5- $\mathrm{HT}_{2 \mathrm{~A} / \mathrm{C}}$ compound 2,5-dimethoxy4-iodophenylisopropylamine (DOI) disrupts PPI via agonist activity at the 5- $\mathrm{HT}_{2 \mathrm{~A}}$ receptor subtype (Padich et al. 1996; Sipes and Geyer 1995b). In addition, the 5- $\mathrm{HT}_{1 \mathrm{~B}}$ receptor also has been implicated in the regulation of PPI (Sipes and Geyer 1994). In concert with these findings, 5-HT-releasing compounds such as MDMA and N,ethylmethylenedioxyamphetamine (MDE) produce partial disruptions of PPI in rats (Mansbach and Geyer 1989; Padich 1993; Kehne et al. 1996; Padich et al. 1996). The habituation of startle, especially tactile startle elicited by airpuff stimuli, also is affected by serotonergic manipulations. Specifically, 5- $\mathrm{HT}_{2}$ agonists decrease and $5-\mathrm{HT}_{2}$ antagonists increase the rate of tactile startle habituation (Geyer et al. 1978; Geyer and Tapson 1988). Similarly, 5-HT releasers, such as MDMA, appear to reduce startle habituation via a fluoxetine-sensitive mechanism (Kehne et al. 1992), whereas 5-HT depletions produced by such toxins as parachloroamphetamine (PCA) or synthesis inhibitors such as parachlorophenylalanine (PCPA) accelerate tactile startle habituation (Geyer and Tapson 1988; Geyer et al. 1990).

The present study was conducted for two reasons. First, to test the hypothesis that AET produces a behavioral profile that is similar to that seen with other indirect 5-HT agonists, we assessed the effect of AET administration on the multiple components of the startle reflex, including reactivity, PPI, and habituation. Second, to test the hypothesis that any observed behavioral effects of AET are attributable specifically to its ability to release presynaptic $5-\mathrm{HT}$, we assessed the ability of a fluoxetine pretreatment to prevent the behavioral effects of AET. As a 5-HT-selective reuptake inhibitor (Wong et al. 1974), fluoxetine blocks the entry of releasing agents into 5-HT terminals via the uptake carrier and thereby prevents drug-induced 5-HT release (Hekmatpanah and Peroutka 1990; Schmidt and Taylor 1990).

\section{MATERIALS AND METHODS}

\section{Subjects}

Male Sprague-Dawley rats (275-300 g; Harlan, San Diego, CA) were housed in pairs and maintained on a reversed 12-hour light/dark schedule (lights off at 0700) in compliance with AAALAC guidelines. Food and water were provided ad libitum. Testing occurred during the dark phase between 0900 and $1500 \mathrm{~h}$. Animals were 
handled and weighed on arrival and allowed to acclimate for 1 week before testing.

\section{Drugs and Solutions}

Alpha-ethyltryptamine (Sigma Chemical Co., St. Louis, MO; acetate salt) was dissolved in nitrogen-purged $0.9 \%$ saline solution and injected SC $(1 \mathrm{ml} / \mathrm{kg}$; AET salt weight). Fluoxetine (Lilly, Indianapolis, IN) was dissolved in $0.9 \%$ saline solution and injected IP in a volume of 2 $\mathrm{ml} / \mathrm{kg}$. Control animals received equivalent injections of $0.9 \%$ saline solution. The pretreatment times before placing the animal into the startle chamber for AET and fluoxetine were 10 and 60 minutes, respectively. All solutions were prepared fresh daily.

\section{Apparatus}

Four startle chambers (SR-LAB, San Diego Instruments, San Diego, CA) were used, each consisting of a Plexiglas cylinder $8.2 \mathrm{~cm}$ in diameter, resting on a $12.5 \times$ $25.5-\mathrm{cm}$ Plexiglas frame within a ventilated enclosure. Background noise and acoustic startle stimuli were provided via a loudspeaker mounted $24 \mathrm{~cm}$ above the animal. Tactile stimuli were delivered via an $8-\mathrm{mm}$ tube to the animal's back. A piezoelectric accelerometer mounted below the Plexiglas frame detected and transduced motion within the cylinder. Stabilimeter readings were rectified, digitized (0-4095), and recorded by a microcomputer and interface assembly (San Diego Instruments), with 1001 -ms readings collected beginning at the stimulus onset. Calibration procedures using a decibel meter were performed between experiments to ensure consistent levels of speaker output and equivalent sensitivities of test chamber stabilimeters, as previously described (Mansbach et al. 1988).

\section{Test Session and Experimental Protocol}

Baseline Matching Procedure. One day prior to testing, a baseline procedure previously described by Peng et al. (1990) was used in assigning animals to experimental or control groups. Briefly, animals were tested in a condensed test session (20 trials) measuring each animal's individual responses to a $40-\mathrm{ms}$ burst of $120-\mathrm{dB}[\mathrm{A}]$ noise alone or following a prepulse $(12 \mathrm{~dB}$ above $70 \mathrm{~dB}$ background). Each animal's responses were averaged across trials, and this value was used to define groups matched for both mean and range. Matching was done within each experiment and separately for each stabilimeter, taking care to ensure in which each animal was retested within the same chamber that they were baselinetested. Since 5-HT may modulate acoustic and tactile startle by virtue of different sensory input pathways (Geyer et al. 1978; Davis 1980), the test session was designed to include both tactile and acoustic stimulus trials.
Experiment 1: AET Dose Response. This experiment was designed to assess the effects of AET $(1.25,2.5,5$, and 10 $\mathrm{mg} / \mathrm{kg}$ ) on acoustic and tactile startle reflexes. It was hypothesized that AET, a 5-HT-releasing agent, would (1) have no effect on tactile or acoustic startle response magnitudes; (2) disrupt PPI; and (3) disrupt habituation to tactile startle stimuli. These doses were chosen in accordance with earlier studies (Krebs and Geyer 1993), as well as pilot data. Each treatment group included 8 to 10 experimentally naive animals. Animals were pretreated with a appropriate volume of saline 60 minutes prior to being placed in the test chamber. This control pretreatment was administered in anticipation of sharing the appropriate groups with experiment 2. Animals were treated with the test compound 10 minutes prior to being placed in the test chamber. The testing included a 5-minute acclimation period, a 60-trial acoustic component to assess PPI, and a subsequent 200-trial tactile component to assess tactile startle habituation. The entire test lasted approximately 55 minutes. Variable intertrial intervals averaging $15 \mathrm{~s}(10-20 \mathrm{~s})$ were used throughout the test. The acoustic test component assessed the ability of 3-, 6-, and 12-db (above 64-dB background) prepulses to inhibit startle responses elicited by $120-\mathrm{dB}$ noise bursts ( 60 trials). Previous studies have shown that these prepulse stimuli do not elicit measurable startle responses by themselves (Mansbach et al. 1988). The acoustic trial types included: Pulse (120-dB noise burst), Pulse preceded by a 3-, 6-, or $12-\mathrm{dB}$ above background (64-dB) prepulse, or no stimulus (Nostim). The tactile stimulus consisted of a 40-ms airpuff (Puff) presented via a pressure regulator set at $25 \mathrm{lb} / \mathrm{in}^{2}$ and split to provide airpuffs to two chambers. Although the air tanks and solenoids were in a different room from the startle chambers, the airpuffs were audible and therefore constitute combined tactile and acoustic stimuli.

Experiment 2: AET/Fluoxetine Challenge. Experiment 1 indicated that, like MDMA, AET has no effect on initial acoustic or tactile startle reactivity. It also was found that AET disrupted PPI and tactile startle habituation in a dose-dependent manner. Based on the results of the dose-response study (Exp. 1), a dose of AET $(5 \mathrm{mg} / \mathrm{kg})$ was selected to be tested after pretreatment with fluoxetine $(10 \mathrm{mg} / \mathrm{kg})$. This dose of fluoxetine is known to block the behavioral effects of MDMA (Callaway et al. 1991). To minimize the number of animals used in the experiments, the control and AET $(5 \mathrm{mg} / \mathrm{kg})$ dose groups were shared with experiment 1 (dose-response study). This dose of AET reliably disrupted PPI and tactile habituation without significantly influencing tactile or acoustic startle reactivity. Based on the results of the dose-response study and previous observations, it was predicted that fluoxetine pretreatment would block AET-induced disruptions of PPI and prevent the disruption of tactile startle habituation. Each pretreatment 
group included 8 to 10 animals. Testing protocol and session were identical to those of experiment 1.

\section{Data Analysis}

For each component of each experiment, startle data were analyzed using a mixed design analysis of variance (ANOVA) with pretreatment and/or treatment as a between-subjects factor(s), and trial type (prepulse intensities or successive trial blocks) as a repeated-measures factor. The criterion for significance was set at $p<.05$. One-way ANOVAs were also conducted on startle magnitude. When significant main effects were found, post hoc comparisons using Tukey's studentized range method were performed. Percent PPI was defined as the percent reduction in startle magnitude in the presence of the prepulse compared to the magnitude in the absence of the prepulse $[100-(100 \times$ magnitude on prepulse trial/magnitude on pulse trial)]. Percentage scores are typically used to minimize the effect of individual variation of startle magnitude on PPI (Mansbach et al. 1988). A large value of this measure indicates that the prepulse inhibited the response to the startling stimulus. Within-session habituation of acoustic startle was tested by comparison of startle reactivity in the first block of Pulse Alone trials ( $n=5$ trials) versus the last block ( $n=5$ trials) prior to the presentation of any tactile stimuli. Tactile habituation data are presented (as per Geyer and Braff 1987) as the first response and 20 blocks of 10 trials. Tactile habituation was also analyzed as a percentage score, which was defined as [100 $\times$ (first block magnitude - last block/first block magnitude)].

\section{RESULTS}

\section{Experiment 1: Dose Analysis of AET Effect}

Figure 2 illustrates the effect of graded doses of AET $(1.25-10 \mathrm{mg} / \mathrm{kg})$ on PPI. The two-factor ANOVA revealed a significant main effect of prepulse intensity $(\mathrm{F}(2,70)=110.3, p<0.0001)$ reflecting the fact that larger prepulses produce greater amounts of PPI. In

AET



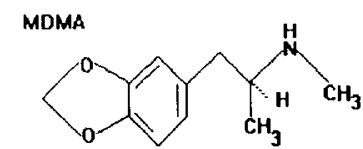

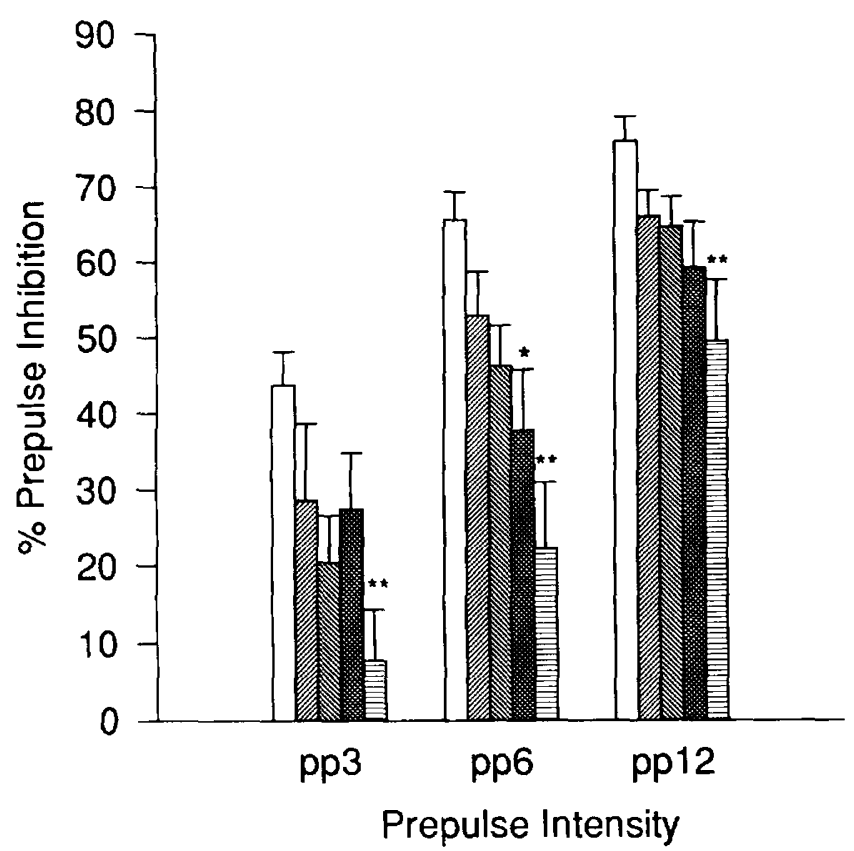

Figure 2. AET dose response study: Percent prepulse inhibition of graded doses of AET $(1.25-10 \mathrm{mg} / \mathrm{kg})$. Groups are indicated by dose of AET ( $N=8$ animals per group). The three measures of PPI are pp3, pp6, and pp12 indicating the intensity of the prepulse preceding the $120-\mathrm{dB}$ pulse. Bars from left to right: saline; AET (mg/kg) 1.25; 2.5; 5.0; and 10.00. *Significant disruption of PPI by AET, $p<.05$.

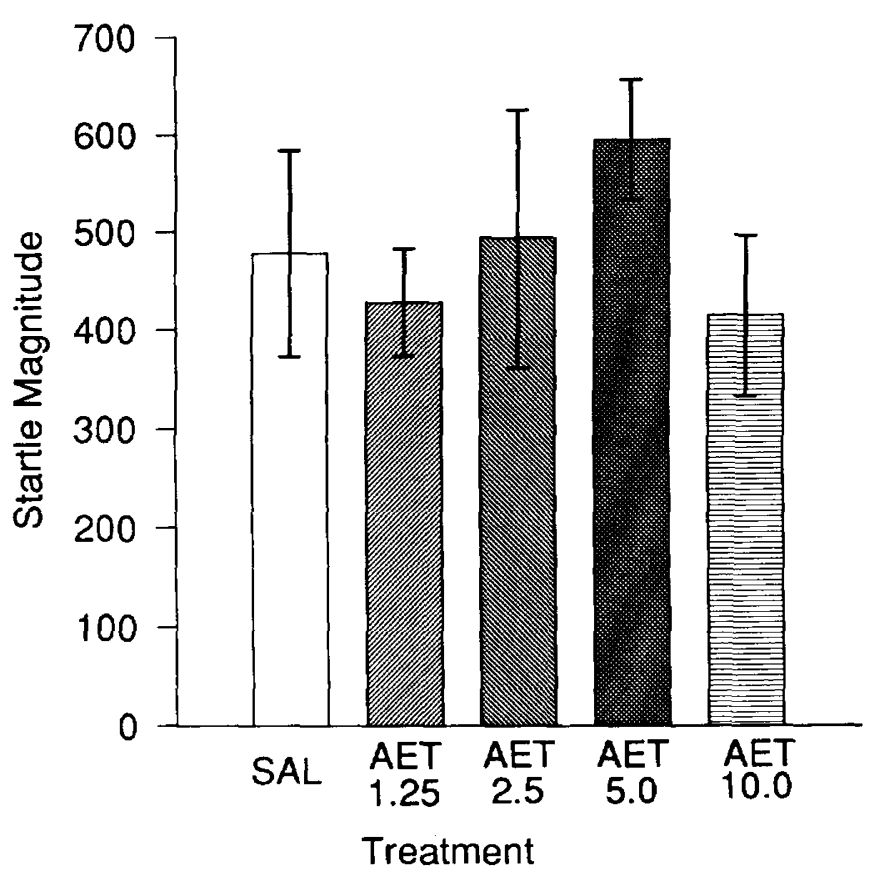

Figure 3. AET dose response study: Mean acoustic startle magnitude for graded doses of AET $(1.25-10 \mathrm{mg} / \mathrm{kg})$. Groups are indicated by dose of AET. Startle was elicited by a $120-\mathrm{dB}$ pulse. Acoustic startle reactivity was not affected by AET.

Figure 1. Comparative structures of 5-HT, AET, and MDMA. 


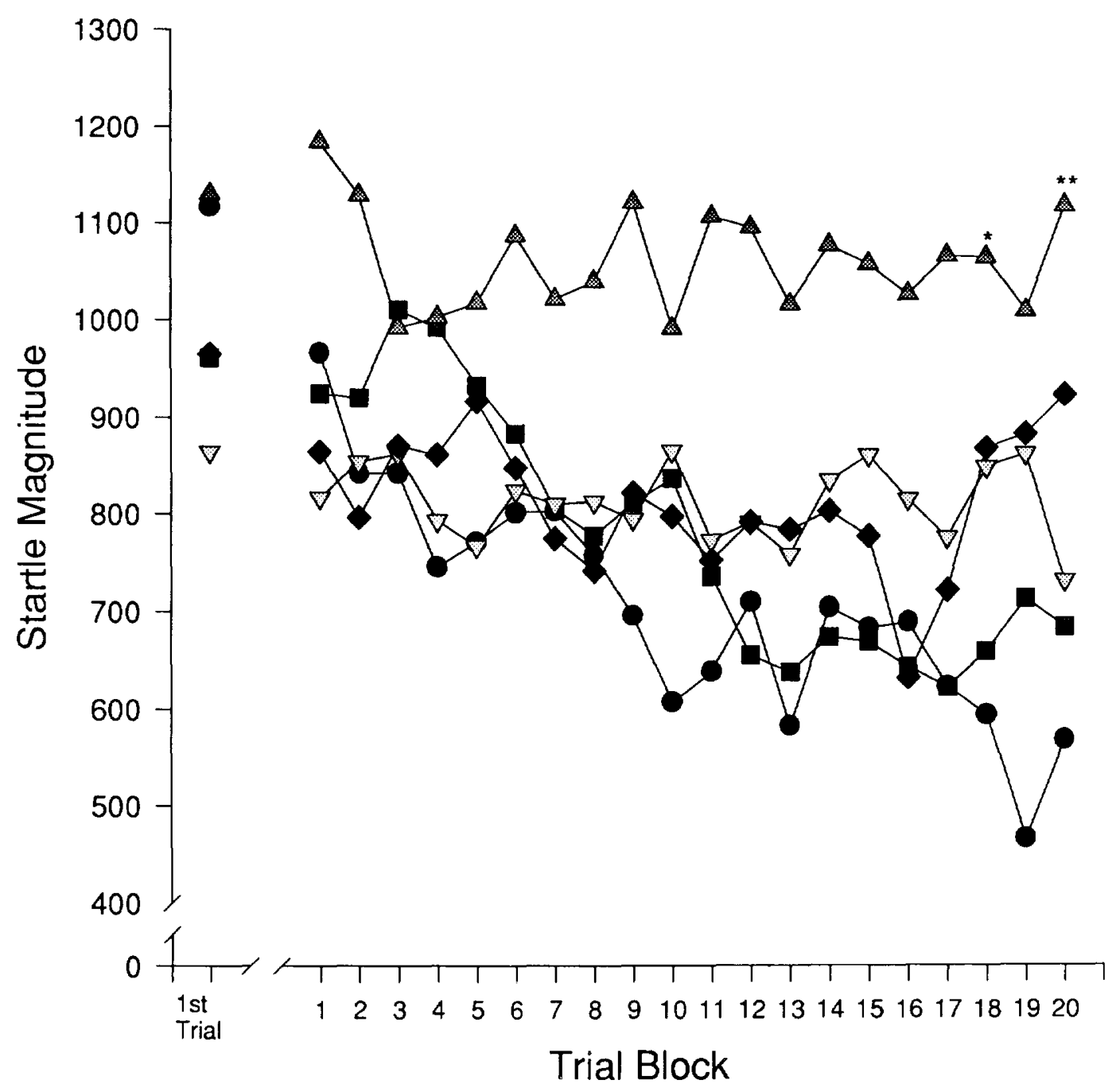

Figure 4. AET dose-response study. Tactile habituation for graded doses of AET (diantonds, $1.25 \mathrm{mg} / \mathrm{kg}$; squares, $2.5 \mathrm{mg} /$ $\mathrm{kg}$; triangles, $5 \mathrm{mg} / \mathrm{kg}$; upside down triangles, $10 \mathrm{mg} / \mathrm{kg}$; circles, saline). Groups are indicated by dose of AET. Startle was elicited by a tactile air puff. The first data point for each group represents the animal's response to the first tactile stimulus presented ( 1 trial), and subsequent data points (1-20) are each representative of one block of trials $(1$ block $=10$ trials). *Significant disruptions of tactile habituation induced by AET, $p<.05$.

confirmation of the original hypothesis, the main effect of drug was also significant $[F(4,35)=6.49, p<.0005]$, indicating that AET reduced PPI percentages compared to saline controls (Figure 2). There was no prepulse-bydrug interaction. PPI difference scores (not shown) also were examined and found to be significantly reduced, agreeing with the PPI percentage score results. AET had no significant effect on the magnitude of startle responses elicited by Pulse Alone $(120-\mathrm{dB})$ trials, whether assessed as the first block of trials or as average of all Pulse-Alone trials across the acoustic component of the session (Figure 3). Furthermore, a comparison between the first and last blocks of Pulse Alone trials (5 trials / block) revealed normal acoustic startle habituation.

AET also disrupted tactile habituation, as reflected by a significant drug-by-trial-blocks interaction $[F(76,665)=$
2.39, $p<.0001]$, as shown in Figure 4. In addition, the main effects of drug $[F(4,35)=2.76, p<.05]$ and trial blocks $[F(19,665)=5.93, p<.0001]$ were significant. Habituation percentage and difference scores also were examined to further analyze AET-induced disruption of tactile habituation. One-way ANOVAs demonstrated that AET significantly reduced tactile startle habituation assessed by both percentage $[(F(4,35=6.70, p<$ $.005)]$ and difference $[(F(4,35)=5.18, p<.005]$ scores (data not shown). As in the acoustic component of the session, the initial level of tactile startle reactivity was not significantly affected by AET (Figure 4).

\section{Experiment 2: Fluoxetine Antagonism of AET}

As shown in Figure 5, the disruptive effect of $5 \mathrm{mg} / \mathrm{kg}$ AET on PPI was blocked by the 5-HT uptake blocker 
fluoxetine, as confirmed by the pretreatment-by-treatment interaction $[F(1,32)=5.64, p<.05]$ in the absence of significant main effects. Neither pretreatment nor treatment interacted significantly with the prepulse intensity factor (Figure 5). There were no significant effects of either pretreatment or treatment on measures of Pulse Alone startle reactivity. The mean startle magnitudes for the four groups were: $478.3 \pm 105.5$ saline/saline; $594.2 \pm 132.5$ saline/AET; $324.9 \pm 65.6 \mathrm{FLX} /$ saline; and $559.9 \pm 103.6$ FLX/AET.

The 5-mg/ kg AET-induced disruption of tactile habituation was attenuated by pretreatment with $10 \mathrm{mg} /$ $\mathrm{kg}$ fluoxetine (Figure 6). This conclusion was supported by a significant three-way interaction (pretreatment-bytreatment-by-trial-blocks) $[F(19,608)=2.11, p<.005]$. In addition, the two-way interaction between pretreatment and treatment was significant $[F(1,32)=4.53, p<$ .05]. Other than the main effect of trial-blocks, no other significant effects were noted. Pairwise two-way ANOVAs were used to identify the source of the triple interaction. Comparing the saline/saline versus the saline/AET groups confirmed that $5 \mathrm{mg} / \mathrm{kg}$ AET disrupted habituation [treatment-by-trial-block interaction, $[F(19,266)=$



Figure 5. Fluoxetine challenge study. Percent prepulse inhibition for fluoxetine $(10 \mathrm{mg} / \mathrm{kg}$ ) versus AET $(5 \mathrm{mg} / \mathrm{kg})$. Groups are indicated by pretreatment and treatment (bars from left to right: saline vs. saline; saline vs. $5 \mathrm{mg} / \mathrm{kg} \mathrm{AET}$; $10 \mathrm{mg} / \mathrm{kg}$ FLX vs. saline; $10 \mathrm{mg} / \mathrm{kg}$ FLX vs. $5 \mathrm{mg} / \mathrm{kg} \mathrm{AET;}$ $N=18,18,10$, and 10 respectively). The three measures of PPI are pp3, pp6, and pp12 indicating the intensity of the prepulse preceding the $120-\mathrm{dB}$ pulse. ${ }^{*}$ Significant disruption of PPI by AET, $p<.05$.
$2.20, p<.005]$. Similarly, comparing saline/saline versus the FLX/saline groups confirmed that $10 \mathrm{mg} / \mathrm{kg}$ fluoxetine also disrupted habituation [treatment-bytrial-block interaction, $F(19,304)=3.09, p<.0001]$, confirming a previous report (Geyer and Tapson 1988). Validating the hypothesis that fluoxetine pretreatment would block the effect of the AET treatment, the difference between the FLX/saline and FLX/AET groups was not significant $[F(19,342)<1.0, N S]$. As in the doseresponse study, both habituation difference and percentage scores were also analyzed. In both cases, the pretreatment-by-treatment interactions were significant $[F(1,32)=4.99, p<.05 ; F(1,32)=11.15, p<.005$, respectively]. Post hoc comparisons confirmed that AET disrupted tactile startle habituation in saline-pretreated animals but not in fluoxetine-pretreated animals.

\section{DISCUSSION}

The results of these experiments support the hypotheses that AET produces behavioral effects similar to those observed after administration of MDMA, PCA, or other 5-HT releasers and does so by acting as an indirect 5-HT agonist. Specifically, AET (1.25 to $10 \mathrm{mg} / \mathrm{kg}$ ) decreased PPI of acoustic startle and reduced the habituation of tactile startle without significantly affecting startle reactivity. These effects of AET were absent in rats pretreated with the 5-HT uptake inhibitor fluoxetine, which prevents the release of presynaptic 5-HT induced by indirect 5-HT agonists (Hekmatpanah and Peroutka 1990; Schmidt and Taylor 1990). Thus, the disruptions of PPI and habituation produced by AET appear to depend on the release of endogenous 5-HT from serotonergic presynaptic terminals.

In rats, PPI is disrupted by a variety of manipulations that activate central serotonergic systems, including direct agonists at $5-\mathrm{HT}_{1 \mathrm{~A}}, 5-\mathrm{HT}_{1 \mathrm{~B}}$, or $5-\mathrm{HT}_{2 \mathrm{~A}}$ receptors (Padich et al. 1996; Rigdon and Weatherspoon 1992; Sipes and Geyer 1994, 1995a) and indirect agonists such as MDMA, MDE, or fenfluramine (Mansbach et al. 1989; Kehne et al. 1996). The present finding that AET disrupts PPI is thus consistent with the effects of both direct 5-HT agonists and other indirect 5-HT agonists. Fenfluramine-induced deficits in PPI are attenuated by $5-\mathrm{HT}_{2}$ antagonists, suggesting that auditory PPI is modulated by $5-\mathrm{HT}_{2}$ receptors (Padich et al. 1996). By contrast, these fenfluramine-induced disruptions in PPI were not attenuated by the dopamine $\mathrm{D}_{2}$ antagonist haloperidol (Kehne et al. 1996), suggesting that these disruptions are independent of the dopamine systems that modulate PPI (Swerdlow et al. 1990a, 1990b; Wan and Swerdlow 1993). Although further studies will be required to determine the specific 5-HT receptors contributing to the effect of AET on PPI, the $5-\mathrm{HT}_{2 \mathrm{~A}}$ receptor is a strong candidate. 




Figure 6. Fluoxetine challenge study. Tactile habituation for fluoxetine $(10 \mathrm{mg} / \mathrm{kg})$ and AET $(5 \mathrm{mg} / \mathrm{kg})$. Groups are indicated by pretreatment (saline and fluoxetine) and treatment (saline or AET). Circles, saline; triangles, FLX vs. saline; squares, AET vs. saline; upside-down triangles, FLX vs. AET. The first data point for each group represents the animal's response to the first tactile stimulus presented (1 trial), and subsequent data points (1-20) are each representative of one block of trials (1 block $=10$ trials). *Significant reversal of AET-induced deficits in tactile habituation by fluoxetine pretreatment.

Fluoxetine pretreatment blocked the AET-induced disruption of PPI. These results are consistent with an earlier finding that MDMA-induced disruption of PPI is blocked with fluoxetine pretreatment (Padich 1993) or pretreatment with the selective 5-HT uptake blocker MDL 28,618A (Kehne et al. 1996). The ability of fluoxetine to attenuate these treatment-induced effects on PPI supports the hypothesis that MDMA- and AET-induced effects depend on the presynaptic uptake carrier. Presumably, like MDMA, AET must enter the presynaptic serotonergic terminal via the uptake carrier to induce a release of 5-HT. To some degree, AET, again like MDMA, also may enter catecholamine terminals and induce some release of catecholamines. Because of the selectivity of fluoxetine for the 5-HT uptake carrier relative to catecholamine uptake carriers (Wong et al. 1974), the blockade by fluoxetine of the effects of AET indicates that these behavioral effects are attributable to 5-HT rather than catecholamine release.

In rats, startle habituation is altered by manipulations that influence central serotonergic systems. Specifically, tactile habituation is facilitated by $5 \mathrm{HT}_{2}$ antagonists, such as cyproheptadine, cinanserin, ritanserin, and ketanserin, as well as 5-HT-depleting agents, such 
as PCA and PCPA (Geyer and Tapson 1988; Geyer et al. 1990). Conversely, tactile habituation is reduced by direct $5-\mathrm{HT}_{2}$, but not $5-\mathrm{HT}_{1 \mathrm{~A}}$, agonists or by $5-\mathrm{HT}$ reuptake blockers such as fluoxetine (Geyer et al. 1978; Geyer and Tapson 1988). In addition, indirect 5-HT releasers produce disruptions of tactile habituation that are attenuated after fluoxetine pretreatment (Kehne et al. 1992). The present studies extend these observations by demonstrating that 1.25 to $10 \mathrm{mg} / \mathrm{kg}$ AET disrupted habituation to tactile startle stimuli. It could be argued that the observed AET-induced disruptions of habituation could be the result of a delayed onset of the drug effect, producing an increase in startle in later trials but not in earlier ones. It should be noted, however, that AET had significant behavioral effects in the acoustic component of the test session, prior to the first of the tactile stimulus trials. Hence, although it remains possible that AET could have delayed releasing effects, it appears that the compound was active at the beginning of the tactile habituation test and that the failure of AET to increase startle in the first block of the tactile component cannot be attributed to pharmacokinetics, but instead is due to the animals' experience with the stimuli. That is, the effect likely reflects an influence on the process of habituation.

As with the effects of AET on PPI, pretreatment with fluoxetine prevented the effects of AET on tactile startle habituation. This observation indicates that the AETinduced disruption of tactile habituation was due to its ability to release endogenous 5-HT from presynaptic serotonergic terminals, as discussed. In addition, it was observed that fluoxetine produced a disruption of tactile startle habituation but did not disrupt PPI. This finding is consistent with previous work indicating that $10 \mathrm{mg} / \mathrm{kg}$ fluoxetine significantly reduced tactile startle habituation in a similar test paradigm (Geyer and Tapson 1988). Previous studies have addressed the effects of presynaptic manipulations on startle habituation, thereby indicating a mechanism by which fluoxetine administration alone might be disrupting tactile startle habituation in the present and previous experiments (Geyer and Tapson 1988).

It has been hypothesized that the starting airpuff stimuli themselves induce presynaptic release of 5-HT. Phasic exteroceptive stimuli are reported to induce bursts of firing in serotonergic neurons (Trulson and Jacobs 1979), which presumably would result in the release of 5-HT within specific systems. More specifically, it has been demonstrated that the experience of tactile startle testing increases 5-HT use in both the median raphe nucleus and the hippocampus (Geyer et al. 1982). Presumably, by blocking reuptake, fluoxetine administration potentiates the actions of this released 5-HT and reduces tactile startle habituation. It should be noted that this disruption was specific to tactile, and not acoustic, startle habituation, indicating a possible modality-specific effect. The air puff stimuli used have both an acoustic and a tactile component and typically produce more gradual habituation than do acoustic stimuli. Studies addressing the effects of acoustic startle on 5-HT content of midbrain raphe neurons, as well as manipulations of testing paradigms could test the possible relevance of stimulus modality and/or complexity to the failure of fluoxetine to affect either habituation or PPI during acoustic startle testing.

Previous studies in rats have shown that the substituted amphetamine MDMA and the tryptamine derivative AET produce similar changes in locomotor and exploratory behaviors (Krebs and Geyer 1993). That these locomotor-activating effects of both MDMA and AET were blocked by pretreatment with fluoxetine (Callaway et al. 1990; Krebs and Geyer 1993), suggests that the two compounds may share a common mechanism of central 5-HT action. The present findings lend further credibility to the hypothesis that, like MDMA, the behavioral effects of AET in both startle and locomotor paradigms are mediated via the release of presynaptic 5-HT and that the effects of indirect 5-HT agonists differ from those of either direct 5-HT agonists or indirect dopamine agonists. Therefore, AET can be classified as a tryptamine-based indirect 5-HT agonist. Thus, AET may be a useful tool to study serotonergic systems, much as amphetamine has been used as a tool in assessing dopaminergic system function. As such, these findings are directly relevant to studies of serotonergic functions and dysfunctions in various psychiatric populations, including OCD and schizophrenia.

The intrusive, undesired thoughts experienced by schizophrenia or OCD patients could be interpreted as deficits in sensory filtering or cognitive gating mechanisms related to processes such as PPI and habituation (Braff and Geyer 1990; Swerdlow et al. 1993). In OCD, obsessional symptoms have been alleviated in some cases by treatment with 5-HT reuptake inhibitors (Barr et al. 1992). Similarly, the serotonergic system has been implicated in the pathology and treatment of schizophrenia. Several current (e.g., clozapine, a compound with high affinity for the $5-\mathrm{HT}_{2}$ receptor), as well as putative (i.e., MDL 100,907, a 5- $\mathrm{HT}_{2 \mathrm{~A}}$ antagonist), antipsychotic medications have been developed to target the serotonergic system. AET is a useful tool to assess the effects of presynaptic serotonin release and, consequently, may facilitate neurobiological studies of mechanisms relevant to pharmacotherapies for OCD and/or schizophrenia.

\section{ACKNOWLEDGMENTS}

The authors gratefully acknowledge the helpful comments and insight provided by Thomas Eagle Sipes, Ph.D., during the preparation of this manuscript. This work was supported 
by grants from the National Institute on Drug Abuse (R02DA02925) and the National Institute of Mental Health (NIMH) (R37MH42228). M. A. Geyer was supported by a Research Scientist Award from NIMH (K05MH01228). D. L. Martinez was supported by NIMH grant R01MH52885.

\section{REFERENCES}

Baker GB, Hiob LE, Martin IL, Mitchell PR, Dewhurst WG (1980): Interactions of tryptamine analogs with 5-hydroxytryptamine and dopamine in rat striatum in vitro. Proc West Pharmacol Soc 23:167-170

Barr LC, Goodman HK, Price LH, McDoogle CJ, Charney DS (1992): The serotonin hypothesis of obsessive compulsive disorder: Implications of pharmacologic challenge studies. J Clin Psychiatr 53(suppl):17-28

Braff DL, Geyer MA (1990): Sensorimotor gating and schizophrenia. Arch Gen Psychiatry 47:181-188

Braff DL, Stone C, Callaway E, Geyer MA, Glick ID, Bali L (1978): Prestimulus effects on human startle reflex in normals and schizophrenics. Psychophysiology 15:339_ 343

Braff DL, Grillon DC, Gever MA (1992): Gating and habituation of the startle reflex in schizophrenic patients. Arch Gen Psychiatr 49:206-215

Callaway CW, Wing LL, Geyer MA (1990): Serotonin release contributes to the locomotor stimulant effects of 3,4methylenedioxymethamphetamine in rats. J Pharmacol Exp Ther 254:456-464

Callaway CW, Nichols DE, Paulus MP, Geyer MA (1991): Sesrotonin release is responsible for the locomotor hyperactivity in rats indicted by derivatives of amphetamine related to MDMA. In Fozard JR, Sazena PR (eds), Serotonin: Molecular Biology, Receptors and Functional Effects, Basel, Birkhauser, 491-505

Davis M, Astrachan DJ, Kass E (1980): Excitatory and inhibitory effects of serotonin on sensorimotor reactivity measured with acoustic startle. Science 209:521-523

Davis M, Casella JV, Wrean WH, Kehne JH (1986): Serotonin receptor subtype agonists: Differential effects on sensorimotor reactivity measured with acoustic startle. Psychopharmacol Bull 22:837-843

Federal Register (1993): 58:13533, March 12

Geyer MA (1995): Serotonergic functions in arousal and motor activity. Behav Brain Res 73:31-35

Geyer MA, Braff DL (1987): Startle habituation and sensorimotor gating in schizophrenia and related animal models. Schizophren Bull 13:643-668

Geyer MA, Tapson GS (1988): Habituation of tactile startle is altered by drugs acting on serotonin-2 receptors. Neuropsychopharmacology 1:135-147

Geyer MA, Peterson LR, Rose GJ, Horwitt DD, Light RK, Adams LM, Zook JA, Hawkins RL, Mandel AI (1978): Effects of lysergic acid diethylamide and mescalinederived hallucinogens on sensory integrative function: Tactile startle. J Pharmacol Exp Ther 207:837-847

Geyer MA, Flicker CE, Lee EHY (1982): Effects of tactile starthe on serotonin content of midbrain raphe neurons in rats. Behav Brain Res 4:369-376
Geyer MA, Swerdlow NR, Mansbach RS, Braff DL (1990): Startle response models of sensorimotor gating and habituation deficits in schizophrenia. Brain Res Bull 25:485-498

Geyer MA, Callaway CW (1994): Behavioral pharmacology of ring-substitued amphetamine analogs. In Cho AK, Segal DS (eds), Amphetamine and Its Analogs: Neuropsychopharmacology Toxicology and Abuse, New York, Academic Ps pp 177-208

Glennon RA (1993): MDMA-like stimulus effects of alphaethyltryptamine and the alpha-ethyl homolog of DOM. Pharmacol Biochem Behav 46:459-462

Graham F (1975): The more or less startling effects of weak prestimuli. Psychophysiology 12:238-248

Hekmatpanah CR, Peroutka SJ (1991): 5-hydroxytryptamine uptake blockers attenuate the 5-hydroxytryptaminereleasing effect of 3,4-methylenedioxymethamphetamine and related agents. Eur J Pharmacol 177:95-98

Hoffman HS, Searle JL (1968): Acoustic and temporal factors in the evocation of startle. J Acoust Sco AM 43:269-282

Kehne JH, McCloskey TC, Taylor VL, Black CK, Fadayel GM, Schmidt GJ (1992): Effects of the serotonin releasers 3,4--methylenedioxymethamphetamine (MDMA), 4-chloroamphetamine (PCA) and fenfluramine on acoustic and tactile startle reflexes in rats. J Pharmacol Exp Ther 260:78-89

Kehne JH, Padich RA, McCloskey TC, Taylor VL, Schmidt CJ (1996): 5-HT modulation of auditory and visual sensorimotor gating: I. Effect of 5-HT releasers on sound and light prepulse inhibition in Wistar rats. Psychopharmacology 124:95-106

Krebs KM, Geyer MA (1993): Behavioral characterization of alpha-ethyltryptamine, a tryptamine derivative with MDMA-like properties in rats. Psychopharmacology 113:284-287

Mansbach RS, Geyer MA, Braff DL (1988): Dopaminergic stimulation disrupts sensorimotor gating in the rat. Psychopharmacology 94:507-514

Mansbach RS, Braff DL, Geyer MA (1989): Prepulse inhibition of the acoustic startle response is disrupted by N-ethyl-3,4-methylenedioxyamphetamine (MDEA) in the rat. Eur J Pharmacol 167:49-55

Padich RA (1993): Role of serotonin in an animal model of defective sensorimotor gating in schizophrenia. Dissertation, Department of Psychology, University of Cincinnati, $\mathrm{OH}$

Padich RA, McCloskey TC, Kehne JH (1996): 5-HT modulation of auditory and visual sensorimotor gating: II. Effects of the 5- $\mathrm{HT}_{2 \mathrm{~A}}$ antagonist MDL 100,907 on disruption of sound and light prepulse inhibition produced by 5-HT agonists in Wistar rats. Psychopharmacology 124:107-116

Peng RY, Mansbach RS, Braff DL, Geyer MA (1990): A $D_{2}$ dopamine receptor agonist disrupts sensorimotor gating in rats: Implications for dopaminergic abnormalities in schizophrenia. Neurophsychopharmacology 3:211-218.

Rigdon GC, Weatherspoon JK (1992): 5-hydroxytryptamine 1 a receptor agonists block prepulse inhibition of acoustic startle reflex. J Pharmacol Exp Ther 263:486-493

Schmidt CJ, Taylor VL (1990): Reversal of the acute effects of 
3,4-methylenedioxymethamphetamine by 5-HT uptake inhibitors. Eur J Pharmacol 181:133-136

Sipes TA, Geyer MA (1994): Multiple serotonin receptor subtypes modulate prepulse inhibition of the startle response in rats. Neuropharmacology 33:441-448

Sipes TA, Geyer MA (1995a): 8-OH-DPAT disruption of prepulse inhibition in rats: Reversal with $(+)$ WAY 100,135 and localization of site of action. Psychopharmacology 117:41-48

Sipes TE, Geyer MA (1995b): DOI disruption of prepulse inhibition of startle in the rat is mediated by $5-\mathrm{HT}_{2 \mathrm{~A}}$ and not by $5-\mathrm{HT}_{2 \mathrm{C}}$ receptors. Behav Pharmacol 6:839-842

Swerdlow NR, Braff DL, Masten VL, Geyer MA (1990a): Schizophrenic-like sensorimotor gating abnormalities in rats following dopamine infusion into the nucleus accumbens. Psychopharmacology 101:414-420

Swerdlow NR, Braff DL, Geyer MA (1990b): GABAergic projection from nucleus accumbens to ventral pallidum mediates dopamine-induced sensorimotor gating deficits of acoustic startle in rats. Brain Res 532:146-150
Swerdlow NR, Benbow CH, Zisook S, Geyer MA, Braff DL (1993): A preliminary assessment of sensorimotor gating in patients with obsessive compulsive disorder. Biol Psychiatr 33:298-301

Swerdlow NR, Paulsen J, Braff DL, Butters N, Geyer MA, Swenson MR (1995): Impaired prepulse inhibition of acoustic and tactile startle response in patients with Huntington's disease. J Neurol Neurosurg Psychiatr 58:192-200

Trulson ME, Jacobs BL (1979): Raphe unit activity in freely moving cats: Correlation with level of behavioral arousal. Brain Res 163:135-150

Wan FJ, Fwerdlow NR (1993): Intra-accumbens infusion of quinpirole impairs sensorimotor gating of acoustic startle in rats. Psychopharmacology 113:103-109

Wong DT, Horng JS, Bymaster FP, Hauser KL, Molloy BB (1974): A selective inhibitor of serotonin uptake: Lilly $110140,3-(\rho$-trifluoromethylphenoxy)-N-methyl-3-phenylpropylamine. Life Sci 15:471-479 